\title{
The effect of heat acclimation or acclimatisation on physiological markers of heat adaptation: preliminary meta-analysis data
}

\author{
Christopher J Tyler $^{1 *}$, Tom Reeve ${ }^{1}$, Gary J Hodges², Stephen S Cheung ${ }^{2}$ \\ From 15th International Conference on Environmental Ergonomics (ICEE XV) \\ Portsmouth, UK. 28 June - 3 July 2015
}

\section{Introduction}

Exercise in the heat places a greater physiological strain upon the body than exercising in temperate conditions, so a number of strategies have been adopted to attenuate this strain. Heat acclimation (or acclimatisation) (HA) has regularly been reported to induce beneficial cardiovascular and thermoregulatory adaptations. However, the magnitudes of benefit reported range from none to substantial, and the differences reported may be due to a wide range of HA protocols being used. The aim of this meta-analysis was to quantify the magnitude of effect that HA has on key physiological markers of adaptation, and to see whether the magnitude of effect is related to the volume or intensity of heat stress experienced.

\section{Methods}

The PubMed database was searched (09/01/15) using the first-order search terms acclimation, acclimatization, acclimatisation and adaptation and second-order search terms heat, exercise, performance, capacity and training.
Using the four-stage process identified in the PRISMA statement the initial number of results $(9,369)$ was reduced to 92 . Data (N, mean, SD) were extracted from these articles in duplicate or triplicate. A subset of the data ( $\mathrm{n}=46$ manuscripts) is presented here; manuscripts were included if resting core temperature $\left(\mathrm{T}_{\text {core }}\right)$, resting heart rate (HR), resting plasma volume (PV) and/or core temperature at sweat onset ( $\left.T_{\text {sweat onset }}\right)$ data were reported. All HA protocols regardless of duration, frequency, ambient conditions or exercise modality were used. Hedge's $g( \pm 95 \% \mathrm{CI})$ were calculated and Spearman's correlation analyses were performed between the effect size and total $\mathrm{HA}$ time $\left(\mathrm{HA}_{\text {time }}\right)$, and HA temperature $\left(\mathrm{HA}_{\text {temp }}\right)$.

\section{Results}

The 46 manuscripts reviewed used a mean (SD) of $9(0)$ [range: 4 - 16] HA sessions separated by $0(0)$ [0 - 1.5] days. Total $\mathrm{HA}_{\text {time }}$ was $868(558) \min [150-2,880]$, and the $\mathrm{HA}_{\text {temp }}$ and $\mathrm{HA}_{\text {humidity }}$ were $39(5){ }^{\circ} \mathrm{C}[28-50]$ and 36 (16) \% [14 - 86], respectively.

Table 1. The effect of $H A$ on resting $T_{\text {core }}$, resting $H R$, resting $P V$ and $T_{\text {sweat onset }}$

\begin{tabular}{|c|c|c|c|c|c|c|c|}
\hline & Articles & Groups & $\mathbf{N}$ & Hedges $g(95 \% \mathrm{Cl})$ & Mean $\Delta$ & $\mathrm{HA}_{\text {time }}$ & $H A_{\text {temp }}$ \\
\hline Resting $T_{\text {core }}$ & 35 & 40 & 372 & $-0.62(-0.77,-0.47)$ & $-0.17 \pm 0.13^{\circ} \mathrm{C}$ & $r=-0.01^{\mathrm{NS}}$ & $r=0.02^{\mathrm{NS}}$ \\
\hline Resting HR & 21 & 27 & 247 & $-0.60(-0.78,-0.41)$ & $-5 \pm 4$ bpm & $r=-0.20^{\mathrm{NS}}$ & $r=-0.13^{\mathrm{NS}}$ \\
\hline Resting PV & 17 & 18 & 183 & $+0.57(0.36,0.79)$ & $+3.5 \pm 3.6 \%$ & $r=-0.37^{\mathrm{NS}}$ & $r=-0.20^{\mathrm{NS}}$ \\
\hline $\mathrm{T}_{\text {sweat onset }}$ & 6 & 9 & 85 & $-0.88(-1.17,-0.59)$ & $-0.24 \pm 1.3^{\circ} \mathrm{C}$ & $r=-0.83^{* *}$ & $r=-0.29^{\mathrm{NS}}$ \\
\hline
\end{tabular}

${ }^{* *}=\mathrm{P}<0.01 ;{ }^{\mathrm{NS}}=\mathrm{P}=0.07-0.50$

\footnotetext{
* Correspondence: chris.tyler@roehampton.ac.uk

'Department of Sport and Exercise Science, University of Roehampton,

London, UK

Full list of author information is available at the end of the article
} 


\section{Conclusion}

$\mathrm{HA}$ is an effective way to reduce resting $\mathrm{T}_{\text {core }}$ and $\mathrm{HR}$; increase resting $\mathrm{PV}$, and lower the $\mathrm{T}_{\text {sweat onset }}$. The magnitude of effect appears to be independent of $\mathrm{HA}_{\text {time }}$ or $\mathrm{HA}_{\text {temp }}$ for each of the 4 variables with the exception of $\mathrm{T}_{\text {sweat onset }}$, which may be inversely related to $\mathrm{HA}_{\text {time; }}$; however, these latter data are derived from only 6 investigations.

\section{Authors' details}

'Department of Sport and Exercise Science, University of Roehampton, London, UK. Environmental Ergonomics Laboratory, Department of Kinesiology, Brock University, St. Catharines, Canada.

Published: 14 September 2015

- Convenient online submission

- Thorough peer review

- No space constraints or color figure charges

- Immediate publication on acceptance

- Inclusion in PubMed, CAS, Scopus and Google Scholar

- Research which is freely available for redistribution 